\title{
Research on the Ideological Guidance and Effectiveness of the Communist Youth League in the Micro Era
}

\author{
Qinyi Li ${ }^{*}$ \\ Panzhihua University, Panzhihua 617000, Sichuan Province, China \\ *Corresponding author: Qinyi Li, 2423695079@qq.com
}

\begin{abstract}
The emergence of carriers such as "micro video," "micro channel," and "micro film," as well as the development of network information technology, have profoundly changed the social operation mode, learning and thinking methods, and interpersonal communication methods, posing new challenges to the Communist Youth League's ideological guidance in the school in terms of content and form. The Communist Youth League's ideological guidance at the school should be practical and realistic, and it should keep up with the times. Improve the Communist Youth League's ideological guidance efficacy in the micro era.
\end{abstract}

Keywords: Micro era; The Communist Youth League; Ideological guidance

Publication date: December 2021; Online publication: January 24, 2022

\section{Introduction}

China Internet Network Information Center produced a statistics study on the country's Internet development. According to the estimate, China will have 888 million short video consumers by June 2021, accounting for $87.8 \%$ of Internet users. It is one of the most popular sources of material for individuals to consume in their spare time. The micro era's beneficiaries, beneficiaries, and aborigines are students. They are an essential means for students to get information, engage in society, and voice their thoughts, which presents the Communist Youth League of the school with new potential and problems in terms of ideological guidance. The Communist Youth League of the University promotes the Central Committee of the Communist Youth League's reform plan, accelerates the path transformation of the Communist Youth League of the University's ideological guidance, practically strengthens the coverage and guidance of youth groups, and fully realizes the Communist Youth League of the University's important role in uniting and leading young college students to listen to a message.

\section{Analysis on the current situation of the ideological guidance of the Communist Youth League}

It is the Communist Youth League's responsibility to nurture persons for whom. Using scientific thinking as a guide and students as the core, the school's Communist Youth League may cultivate qualified socialist builders and successors based on the personality traits of students in the micro era.

\subsection{Achievements in the ideological guidance of the Communist Youth League of the University}

The work of the Communist Youth League in the school has formed an operation mechanism with distinctive characteristics, perfect mechanism and enriched activities, which has made remarkable 
achievements in the ideological guidance of the Communist Youth League.

\subsection{The party's youth mass base has been strengthened and improved}

The school Communist Youth League's most essential task is to recruit excellent students to join the party. The Communist Youth League's sense of belonging, repute, and recognition among students has substantially improved, extending and strengthening the party's youth mass base. According to data, around one-fifth of Communist Youth League members in universities and one-third of double-first-class colleges and universities join the party. It is clear that the Communist Youth League at the school has had a great deal of success in recruiting good kids to join the party.

\section{Promote practical education and achieve results}

Knowledge comes from practice and in turn guide's practice. The Communist Youth League of the university always adheres to the practice of social responsibility, serving the needs of the country and combining with practical education, so as to build a practical carrier integrating voluntary service, school learning, public welfare activities and social practice. This is to promote the effectiveness of practical education ${ }^{[1]}$. Referring to the teaching mode of the first classroom, the Communist Youth League of the university has established close cooperative relations with relevant departments and institutions such as society, government and schools. It was carefully planned and implemented, the second classroom activities, scientifically certified and truthfully recorded the participation experience and achievements of students, and promoted the institutionalization, curriculum, normalization and standardization of students' skill development. Giving full play to the role of the second classroom in promoting and extending the effectiveness of the first classroom teaching has become an important basis for students' comprehensive quality evaluation and an important content of school skill training.

\section{Deficiencies in the ideological guidance of the school Communist Youth League}

According to the actual investigation and inquiry of literature, the ideological guidance effect of the Communist Youth League is not significant, which is reflected in the following two aspects:

First, students must strengthen their support for the Communist Youth League. According to the survey findings, $43 \%$ of league members believe they have played a significant leadership role in events linked to festivals and anniversaries, $41 \%$ of league members are moved to play a leading role, and $16 \%$ of league members are not moved to play a leading role. In the Communist Youth League's social welfare activities, $46 \%$ of league members believed they played a leadership role, $49 \%$ felt they did not play a leading role, and $5 \%$ did not feel they did not play a leading role. When the Communist Youth League carried out activities related to voluntary services and practical activities, $59 \%$ felt that they played a leading role, $30 \%$ felt that they played a general leading role, and $11 \%$ felt that they did not play a leading role.

Second, people have more discourse power in the micro era, which weakens students' authoritative identification with mainstream culture. According to the report, college students spend a significant amount of time online. $40 \%$ of students spend three to five hours per day on the Internet, $30 \%$ spend six to eight hours per day on the Internet, and more than $25 \%$ of students spend more than eight hours per day on the Internet, demonstrating that students are more reliant on the Internet. In terms of the choice of network information types, $73 \%$ of students choose entertainment and leisure, $38 \%$ prefer short video information, and only $46 \%$ pay more attention to the content of news information and current politics on the network, weakening the work carrier led by the traditional Communist Youth League thought. 


\section{The path for the Communist Youth League of the school to improve the effectiveness of ideological guidance}

\subsection{Strengthen network education and promote the development led by network thought}

\subsubsection{Strengthen the construction of working position platform}

The school Communist Youth League utilizes the Internet, enhancing the effectiveness of traditional methods of ideological and political work with modern information technology and scientific means, integrating the role of League organizations and online Youth League organizations, and promoting the use of Weibo, Wechat, TikTok, Quick Hand, and other apps, encouraging students to find new carriers and communication platforms in cyberspace. The school's Communist Youth League employs the "easy class" service project and platform plan to create a comprehensive interactive community that integrates life service, education and teaching, ideological guidance, culture and entertainment, and fully utilizes the role of network education in the construction of "three complete education" [2].

\subsubsection{Strengthen the construction of network content products}

The content of the Communist Youth League's network products should be innovative and inherited, and the combination of practice and theory, to give full play to the initiative, creativity and enthusiasm of the grassroots League organizations, improve the school's Communist Youth League's new media product R\&D and sharing platform, and realize interconnection, co-construction and sharing. The Communist Youth League of the University shall implement the youth lecturer League plan, organize party members and cadres, theoretical experts and young teachers to focus on students' concerns and ideological confusion, organize online live propaganda and face-to-face propaganda and exchange, organize students to shoot Mini dramas, spread positive energy and enrich the ideological guidance content of the Communist Youth League.

\subsubsection{Strengthen the guidance of network public opinion}

From the perspective of implementing the party's ideological work, the school Communist Youth League should promote the development process of network public opinion guidance, give full play to the role of the school Communist Youth League as the supervision team and main force on the network platform. Also, do a good job in the civilized volunteers of the network, vigorously develop a positive and healthy network culture, purify the network ecology, nourish the network space, and create a clean and prosperous network space.

5.2. Strengthen practical education and promote the combination of thought leading theory and practice

5.2.1. Implement the second classroom transcript system of the Communist Youth League of the school

For the purpose of educating people, the Communist Youth League of the school organizes students' social practice, physical quality, innovation, work exercise, public welfare activities, interest and participation in activities. With reference to the operation mechanism of the first classroom, strengthening the relationship between social institutions, government departments and school departments, promotes the development of the second curriculum activities, ensures the results of scientific certification and objective records, achieves the standardization and institutionalization of student development, and combines the second classroom with the first classroom as an important indicator of comprehensive quality evaluation and school talent training. 


\subsubsection{Carry out extensive social practice activities}

The "three trips to the countryside" social practice activity for college students in the summer is designed to help students better understand rural areas, farmers, and agriculture through social practice, as well as to temper their quality, sharpen their will, and improve their ideological realm in a challenging environment. Colleges and universities across the country should actively seek the support of enterprises and institutions, party and government organs, and social forces, and provide more posts and opportunities for students' practical training, as guided by the implementation of the internship plan for college students in central and state systems.

\subsubsection{Vigorously carry out voluntary service activities for college students}

The Communist Youth League of the University encourages more students to act as young volunteers by means of real name certification, promote dedication, service awareness and volunteer spirit, show the spiritual outlook of League members in voluntary service and give play to the exemplary role of League members. The Communist Youth League of the school supports and encourages rural education support activities, encourages the western support plan for school students, pays attention to left behind children, migrant workers' children, disabled organizations, etc., strengthens one-to-one corresponding services of voluntary service projects, and encourages more students to participate in various types of voluntary service activities in their spare time, especially service activities carried out by class Youth League branches, Improve service awareness and enhance social experience. At the same time, encourage voluntary service credit activities and encourage students to carry out voluntary service as a daily life activity.

\subsection{Strengthen service education and solve ideological and practical problems}

\subsubsection{Promote students' innovation, entrepreneurship and excellence}

The Communist Youth League of students held competitions in innovation, entrepreneurship, and excellence, hosted innovation and entrepreneurship education activities, encouraged, cultivated, and provided excellent platforms, improved the "China Youth Science and Technology Innovation Award," organized excellent brand events such as "Challenge Cup" and "creating youth," allowed more young people to participate in activities, and deepened innovation and entrepreneurship education. Give full play to position carriers such as the student entrepreneurship demonstration park, the practical education innovation and entrepreneurship base, student innovation and entrepreneurship classes, and the student innovation and entrepreneurship alliance, hold entrepreneurship training activities, pay attention to college students' breakthroughs and achievements in innovation, entrepreneurship, and practice, and encourage students to make academic decisions.

\subsubsection{Care and help specific student groups}

The Communist Youth League pays timely attention to and promotes the solution of students' difficult needs in talent development, study and life, employment, postgraduate entrance examination, social practice and etc. The Communist Youth League takes advantage of the time period of freshmen entering school and graduates leaving school to help students make learning plans and integrate into campus life, help graduates improve their employment skills and master policy information, and guide them to rural grass-roots units, Northeast China, central and western regions and difficult and remote areas for employment development. The Communist Youth League strengthens students with academic, economic, interpersonal and psychological difficulties, implements assistance policies, pays attention to humanistic care and psychological counseling, carries out effective accurate assistance actions for graduates, improves the construction of psychological sunshine engineering team, determines student tutor plans and activities 
such as sending warmth on holidays ${ }^{[3]}$. The Communist Youth League pays attention to minority students, helps them establish good national consciousness, national concept, religious concept and historical attitude, attaches importance to the work of Hong Kong, Macao, Taiwan and overseas Chinese students studying in the mainland, and guides them to enhance national identity and Chinese national consciousness.

\section{Funding}

This paper is the phased achievement of the Social Science Project of Panzhihua University (Project Number: 2019syb18) in 2019.

\section{Disclosure statement}

The author declares that there is no conflict of interest.

\section{References}

[1] 2018, Propaganda Department of the CPC Central Committee Face to Face in The New Era. People's publishing house, Beijing.

[2] Zhang L, Lin J, 2020, Research on the Ideological Leading Mode of the Communist Youth League in Colleges and Universities from the Perspective of New Media. Contemporary Educational Practice and Teaching Research, 2020(04): 37-38.

[3] Tang C, 2020, On the Problems and Strategies of Leading the Ideological Education of College Communist Youth League Students. Communication and Copyright, 2020(01): 164-166. 